\title{
Homogenisation of climate time series from ICP Forests Level II monitoring sites in Germany based on interpolated climate data*
}

\author{
Daniel ZICHE**, Walter SEIDLING
}

Institute of Forest Ecology and Forest Inventory at the Johann Heinrich von Thünen Institute, Alfred-Möller-Str.1, 16225 Eberswalde, Germany

(Received 31 December 2009; accepted 10 June 2010)

Keywords:

forest monitoring /

climate /

kriging /

homogeneity /

QA/QC

\begin{abstract}
- The aim of our work was to homogenise the meteorological dataset of German ICP Forests Level II sites $(n=73)$ by the aid of interpolations based on climate data from the German meteorological network (DWD).

- For each site daily values of climate variables (temperature, precipitation, solar radiation, relative humidity and wind speed) were interpolated by ordinary kriging after the removal of global trends for each day over a period of $11 \mathrm{y}$. The quality of the method was estimated by cross validation. The standard normal homogeneity test for single shifts was applied repetitively to detect inhomogenities in all time series $(n=594)$ using the interpolated dataset as reference.

- Our results indicate that: the accuracy of the interpolation method was highest for maximum air temperature and lowest for wind speed; homogenisation improved the quality of the climate time series and had the largest impact on solar radiation and wind speed; the correlation of interpolated and measured climate was stronger within the DWD network than within the ICP Forests Level II network, due to a generally higher variance (precipitation) or a systematic deviation (wind speed, minimum air temperature).

- We suggest the use of external climate data for homogenisation procedures within the quality assurance/quality control of the ICP Forests Level II programme. The high prediction errors of precipitation and wind speed demonstrate the need for the on - site survey within the monitoring programme.
\end{abstract}

\section{INTRODUCTION}

Within the last decade it became apparent that the need for monitoring climate impact on ecosystem functions is of major importance. The predicted climate change poses questions to the adaptability of forests to cope with long-term trends and short-term fluctuations as well as extreme events (Innes, 1994). Weather anomalies can have a high spatial and temporal variability which increases as the time resolution increases (Spadavecchia and Wiliams, 2009). Therefore, meteorological information in forested areas is needed, which can be related to different site specific forest health indicators (Solberg et al., 2009).

Since 1985 the ICP Forests monitoring programme runs under the UNECE Convention on Longe-range Transboundary Air Pollution (CLRTAP). It aims to provide information on forest health in relation to the immission load in order to develop air pollution abatement strategies. As one part within the ICP Forests programme intensive monitoring (Level II) is car-

* This manuscript issues from a presentation at the LWF conference, Zürich, September 2009.

** Corresponding author: daniel.ziche@vti.bund.de ried out on more than 800 plots in Europe located within the most important forest ecosystems (de Vries et al., 2003). Meteorological measurements are performed continuously on many of these plots to detect weather extremes and assess climate impact on forest conditions. Currently, efforts were undertaken to adjust the monitoring programme to actual demands.

Typically, of a monitoring programme the largest amount of effort is allocated to data collection, while data quality assessment and data evaluation are often underrepresented (Ferretti et al., 1999; Houston and Hiederer, 2009). To assess the impact of climate extremes on forest health it is crucial to have accurate climate time series. Above environmental monitoring the monitoring of climate has the longest tradition. National weather services can provide climate time series for more than $100 \mathrm{y}$ at numerous locations. Due to the climate change debate a special focus was put on the quality of the time series. Different statistical methods were developed to test if climate time series are free of non-climatic inhomogenities (Peterson et al., 1998). Within the ICP Forests Level II monitoring programme the quality of the meteorological data was routinely estimated to a certain level, but tests for homogeneity have not been performed (Houston and Hiederer, 2009). Therefore we 
Table I. Results of cross validation over a time span of $4018 \mathrm{~d}$, with $n=$ number of stations used for validation, $r^{2}=$ coefficient of determination between measured and interpolated daily climate values, MAE = mean absolute error, PMAE = percentage mean absolute error, DTR $=$ diurnal temperature range.

\begin{tabular}{|c|c|c|c|c|c|c|c|}
\hline \multirow[b]{2}{*}{ Variable } & \multirow[b]{2}{*}{$n$} & \multicolumn{3}{|c|}{ Daily } & \multicolumn{3}{|c|}{ Monthly } \\
\hline & & $r^{2}$ & MAE & PMAE & $r^{2}$ & MAE & PMAE \\
\hline Temperature (max.) & 417 & 0.99 & 0.6 & 4.5 & 1.00 & 0.4 & 2.8 \\
\hline DTR & 417 & 0.91 & 1.0 & 11.7 & 0.96 & 0.6 & 7.0 \\
\hline Precipitation & 161 & 0.84 & 0.8 & 37.7 & 0.89 & 9.8 & 14.4 \\
\hline Rel. humidity & 417 & 0.88 & 3.4 & 4.2 & 0.93 & 2.1 & 2.7 \\
\hline
\end{tabular}

intended to improve the German part of the ICP Forests Level II climate data set by homogenisation.

Tests for homogeneity work with reference data sets, typically data from nearby weather stations. We purposed to compile a reference data set with a geostatistical method. Beside its use for homogenisation, this approach should also give us an answer to the question how close on-site measurements are correlated to interpolated climate data. This question is relevant, because on the one hand the measurements are cost-intensive and on the other hand a dense network of weather stations from the national meteorological services exist especially in Central Europe and spatial interpolation techniques allow estimation of climate values with daily resolution (Hutchinson et al., 2009; Spadavecchia and Wiliams, 2009; Stahl et al., 2006; Thornton et al., 1997). In regions with a high weather station density they can be successfully applied.

The aim of our work was to assess and enhance the quality of the time series by the homogenisation of measured climate data and its comparison to interpolated climate data, and to determine the systematic deviation between both sets of climate time series. Therefore in this work we (1) applied a geostatistical method for climate interpolation and validated their reliability and (2) tested the homogeneity of the climate time series and their improvement due to homogenisation.

\section{MATERIAL AND METHODS}

Our work was restricted to 73 German Level II plots in the ICP Forests monitoring programme, which were equipped with automatic weather stations. The weather stations were either located in open fields close to the plots (66 sites) or the measurements were conducted above the canopy ( 7 sites). One site was equipped with both. In case of measurements above the canopy the distance of the sensors to the canopy was for air temperature 1-2 m, for wind speed up to $8 \mathrm{~m}$. Since 1996 for most of the sites meteorological measurements were performed continuously. The stations were operated by the German federal states. The sub daily data were aggregated to daily values either as sum or mean, max and min and submitted to the Level II database. Within the international Level II database a quality assessment programme was implemented (Houston and Hiederer, 2009). This consists of single parameter tests which check for outliers with range tests and global thresholds. Furthermore, to obtain data uni- formity only daily values were accepted with a daily completeness $\geq 90 \%$.

We used climate data based on daily resolution of climate stations of the German weather service (DWD). The data set contained daily values for mean, maximum and minimum air temperature, sum of precipitation, and means of air humidity, wind speed and solar radiation. The dataset was homogenized (Österle et al., 2006). For the interpolation of temperature, relative humidity and wind speed, data from 417 stations was used, for the interpolation of solar radiation data from 278 stations and for the interpolation of precipitation data from 2344 stations was used (Tab. I). The dataset consisted of daily values and covered the whole time span of the German ICP Forests Level II database from the beginning of 1996 to the end of 2006.

For the interpolation the geographic coordinates of all climate stations were transformed to a projected coordinate system (Lambert Conformal Conic). Meteorological data are not isotropic due to trends caused by elevation, latitude and longitude. Therefore, universal trends in the climate data were removed by fitting a polynomial function with elevation, latitude and longitude as regressors for each day and using the residuals for further evaluations (Proc GLM, SAS 9.2, SAS institute, Carry). The daily variance between the residuals of the different climate stations was calculated (Proc Variogram, SAS 9.2). A small set of variograms were set up and visually inspected in order to calculate starting values and theoretical variogram functions for each variable on a daily resolution. Both were used to parameterize a variogram function for each day and each variable separately by non-linear regression (Proc NLIN, SAS 9.2). An exponential variogram function was selected for all variables with the exception of precipitation. For precipitation a nested variogram model was applied, which comprised of a spherical and an exponential model. Then ordinary kriging was performed based on the variograms (Proc KRIG2D, SAS 9.2). The quality of the method was proved by cross validation. That means that one station value was deleted per time and then this value was interpolated. This was repeated for each station per day which resulted in a total number of kriging operations of days * stations and caused a significant bottleneck in the analyses. Therefore, for precipitation a smaller set of stations was selected $(n=161)$ and their daily values were interpolated by the other stations and used in the subsequent evaluation. Mean least square regression between the kriging estimates and the measured values were conducted (Proc GLM, SAS 9.2). The regression coefficients, mean deviations (ME) and mean absolute errors (MAE) were used to estimate the agreement between measured and interpolated values. 


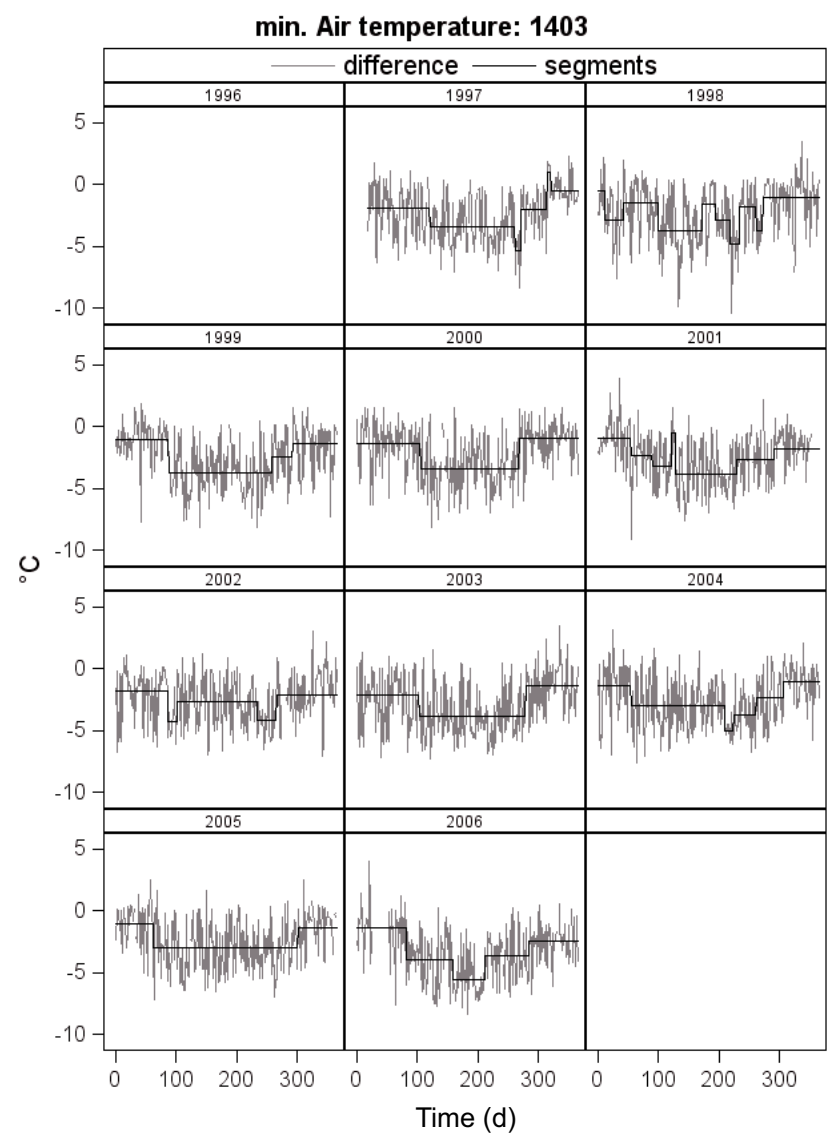

Figure 1. Daily differences of measured and interpolated minimum air temperature at site 1403 in Saxony/Germany (grey line) and averages of homogenous parts of the time series (black line).

Shifts in the measured time series were checked according to the standard normal homogeneity test (SNHT) for single shifts (Alexandersson, 1986), however with modifications: the results of the interpolation for each station and day were used as reference data set. The SNHT is based on differenced time series, where either the ratio or the difference between the measured and the reference time series was calculated (Fig. 1). We used ratios for the variables precipitation, solar radiation, relative humidity, wind speed and differences for the temperature variables. The SNHT could detect only one shift in a series per time. Therefore after the detection of a shift it was necessary to split the series in two sequences and to repeat the test for both sequences separately. This had to be repeated until no significant break was found anymore. After obtaining all significant breaks within a time series the segment which represents the "true" level of the series had to be found. It was difficult to find an objective, operator free method to select this level. We decided to generally select the longest homogenous segment as reference segment, which was within critical limits. The critical limits for ratios were between 0.8 and $1.25 \mathrm{~m}$ for solar radiation, wind speed and rel. humidity and 0.5 and $2 \mathrm{~m}$ for precipitation. The homogenisation procedure caused problems with precipitation due to zero values and large variances. Therefore, both precipitation time series were transformed with a seven day moving operator before the homogenisation procedure started. Furthermore the ratio series were root transformed before standardisation. Only in- homogeneities were taken into account when the resulting segments had a length of at least 90 days. The same procedure was applied to wind speed. To be able to work on the large amount of time series automatically $(n=594)$, we used the macro programme facility within SAS 9.2.

Differences between interpolated and measured, homogenised and non-homogenised datasets were checked by linear regression and on the basis of the mean absolute error (MAE) and the mean error (ME). $t$-tests were applied to check for the differences in the means using the station means as replications. Both was done for the daily and monthly aggregated values.

\section{RESULTS}

The results of the cross validation indicate that the interpolation method yielded for all variables a close relationship between the measured DWD data set and its interpolated counterpart (Tab. I). The $r^{2}$ was lowest for wind speed with 0.7 and considerably higher for the other variables (0.84-0.99, Tab. I). The mean daily temperature could be estimated with a MAE of $0.5^{\circ} \mathrm{C}$ which amounted to $5.8 \%$ of the average. The interpolation of daily minima temperature was less accurate than interpolation of daily maxima. The MAE amounted to $15.3 \%$ for minimum air temperature and $4.5 \%$ for maximum air temperature. Calculating the daily temperature range with both variables yielded a MAE of $11.7 \%$. The accuracy was much lower for precipitation and wind speed, both variables with a high spatial variability. The MAE of precipitation was $0.8 \mathrm{~mm} \mathrm{~d}^{-1}$ or $37.7 \%$ and the MAE of wind speed was $0.9 \mathrm{~ms}^{-1}$ or $36.9 \%$. Relative humidity could be predicted most accurately by the interpolation method, the MAE was $4.2 \%$. The MAE of global radiation was $10.3 \mathrm{~W} \mathrm{~m}^{-2}$ or $8.6 \%$ of the average. The interpolation could not successfully be performed for each day. Most missing values occurred for solar radiation, which was the variable with the lowest station density. Aggregating from daily to monthly values had the most marked effect on precipitation. The MAE was reduced to $14.4 \%$. The MAE of the other variables was reduced to a lesser extend (Tab. I).

The comparison of interpolated and measured values at the Level II sites (Tab. II) yielded higher MAEs and lower $r^{2}$ values than the cross validation based on DWD station data (Tab. I). This was most critical pronounced for precipitation and wind speed. The MAE of precipitation was at DWD sites $1 \mathrm{~mm}$ or $34 \%$ lower compared to the forest sites (Tabs. I, II).

Homogenisation reduced the MAEs. Homogenisation of daily temperatures had less impact. The correlation between interpolated and measured values increased slightly from 0.98 to 0.99 (mean and maximum daily air temperature) or 0.95 to 0.96 (minimum daily air temperature). The MAE of mean daily temperature and maximum daily temperature decreased from $1.0{ }^{\circ} \mathrm{C}$ or $12.0 \%$ to $0.9{ }^{\circ} \mathrm{C}$ or $10.3 \%$ and $1.1{ }^{\circ} \mathrm{C}$ or $8.5 \%$ to $1.0{ }^{\circ} \mathrm{C}$ or $7.8 \%$, respectively, while the MAE of minimum air temperature stayed nearly constant with $1.5^{\circ} \mathrm{C}$ or $38.1 \%$. The absolute changes of daily temperature values due to homogenisation were below $0.1{ }^{\circ} \mathrm{C}$. The differenced time series of minimum and maximum air temperature showed seasonality, with lower differences in winter than in summer for min- 
Table II. Effects of homogenisation of climate time series: Mean error and $r^{2}$ before and after homogenisation, with $r^{2}=$ coefficient of determination between measured and interpolated daily climate values, MAE = mean absolute error, PMAE, percentage mean absolute error, $d=$ mean difference before and after homogenisation, DTR $=$ diurnal temperature range.

\begin{tabular}{|c|c|c|c|c|c|c|c|}
\hline \multirow[b]{2}{*}{ Variable } & \multicolumn{3}{|c|}{ Non-homogenised } & \multicolumn{3}{|c|}{ Homogenised } & \multirow{2}{*}{$d$} \\
\hline & $r^{2}$ & MAE & PMAE & $r^{2}$ & MAE & PMAE & \\
\hline Temperature (max.) & 0.98 & 1.1 & 8.5 & 0.99 & 1.0 & 7.8 & -0.07 \\
\hline DTR & 0.81 & 1.7 & 20.7 & 0.84 & 1.8 & 21.6 & \\
\hline Precipitation & 0.54 & 1.8 & 71.4 & 0.55 & 1.8 & 71.2 & -0.01 \\
\hline Rel. humidity & 0.76 & 6.1 & 7.5 & 0.85 & 5.5 & 6.9 & -0.54 \\
\hline
\end{tabular}

Table III. Comparison of interpolated and homogenised measured time series: Daily average of station means, with $n=$ number of stations, $I=$ interpolated average, $M=$ measured average, $\mathrm{ME}=$ Deviation $(I-M)$, PMAE $=$ Percentage of Deviation, DTR $=$ diurnal temperature range.

\begin{tabular}{lcccccc}
\hline Variable & Unit & $n$ & $I$ & $M$ & ME & PME \\
\hline Temperature & & 75 & 8.4 & 8.0 & 0.4 & 4.8 \\
Temperature (max) & & 75 & 12.4 & 12.2 & 0.3 & 2.2 \\
Temperature (min) & ${ }^{\circ} \mathrm{C}$ & 74 & 4.5 & 4.0 & 0.6 & 14.4 \\
DTR & & 74 & 8.0 & 8.3 & -0.3 & -3.8 \\
Precipitation & $\mathrm{mm}$ & 71 & 2.8 & 2.5 & 0.2 & 8.0 \\
Rel. humidity & $\%$ & 75 & 79.6 & 80.3 & -0.8 & -1.0 \\
Solar radiation & $\mathrm{Wm}^{-2}$ & 74 & 117 & 113 & 4.9 & 4.3 \\
Wind speed & $\mathrm{ms}^{-1}$ & 73 & 2.7 & 2.1 & 0.6 & 30.9 \\
\hline
\end{tabular}

imum air temperature and lower differences in summer compared to winter for maximum air temperature (Fig. 1). Precipitation was less affected by homogenisation. The $r^{2}$ increased only from 0.54 to 0.55 and the MAE remained at $1.8 \mathrm{~mm}$ or $71 \%$. The homogenisation had the largest influence on solar radiation and wind speed data. The $r^{2}$ of solar radiation was 0.88 before homogenisation and 0.92 after, and the MAE was reduced from $23.7 \mathrm{~W} \mathrm{~m}^{-2}$ or $21.7 \%$ to $18.6 \mathrm{~W} \mathrm{~m}^{-2}$ or $16.7 \%$. Solar radiation increased approximately by $4.6 \mathrm{~W} \mathrm{~m}^{-2}$ per day due to homogenisation. The correlation between measured and interpolated wind speed data increased with $r^{2}$ of 0.48 before and 0.55 after homogenisation. The MAE was reduced from $1.3 \mathrm{~ms}^{-1}$ to $1.0 \mathrm{~ms}^{-1}$ or $80 \%$ to $51 \%$. The absolute effect of homogenisation of wind speed was an increase of $0.39 \mathrm{~ms}^{-1}$ on average.

The measured and interpolated daily values of all variables deviated significantly from each other (Tab. III). The interpolated maximum air temperature was on average $0.3{ }^{\circ} \mathrm{C}$ or $2.2 \%$ higher and the mean daily air temperature was on average $0.4{ }^{\circ} \mathrm{C}$ or $4.8 \%$ higher than measured. After homogenisation the deviation of minimum daily air temperature between interpolated to measured data was $0.6{ }^{\circ} \mathrm{C}$ or $14.4 \%$. Interpolated precipitation was on average $0.2 \mathrm{~mm} \mathrm{~d}^{-1}$ or $8 \%$ higher compared to measured values and interpolated wind speed $0.6 \mathrm{~ms}^{-1}$ or $30.9 \%$. Interpolated solar radiation was $4.9 \mathrm{~W} \mathrm{~m}^{-2}$ or $4.3 \%$ per day higher. Interpolated relative humidity was on average $0.8 \%$ lower than measured.

\section{DISCUSSION}

Interpolated climate data provide an adequate tool for homogenisation of meteorological time series. The compilation of a reference series for homogenisation procedures by geostatistical methods is a scientific progress due to its mathematical correctness when compared to other methods. Nevertheless, the accuracy of the method should be carefully assessed. Geostatistical methods have been frequently used for generating meteorological data in non-measured areas. It has been shown by several authors that geostatisitcal methods are superior to simple interpolation techniques (e.g. Luo et al., 2008 (wind speed); Miller et al., 2008 (global radiation); Vicente-Serrano et al., 2003 (precipitation)), but less powerful than approaches which use regional modelling of weather (Daly et al., 2008; Dorninger et al., 2008). The accuracy of the interpolation results depend on the spatial and topographic representativeness of the reference weather stations. The station density was highest for precipitation with $160 \mathrm{~km}^{2}$ per station and lowest for solar radiation with $3200 \mathrm{~km}^{2}$ per station. The other variables were measured with a density of $860 \mathrm{~km}^{2}$ per station. The station density was high and uniform compared to other studies (Hutchinson et al., 2009; Stahl et al., 2006; Thornton et al., 1997). Furthermore the source network reflected a wide range of topography and included also stations at high elevation. Therefore we assume that our interpolation method which combined global regression and ordinary kriging was an adequate approach.

In our work the estimates of the mean and maximum daily temperatures were very close to the measured values. The lower accuracy in the prediction of the minimum daily air temperature compared to the maximum air temperature is in accordance with other findings and can be attributed to cold air drainage and the latent heat of water condensation, when the minimum temperature is close to dewpoint temperature (Hutchinson et al., 2009).

Precipitation exhibits generally a large variability in space and time. The nature of the precipitation events, large scale or convective, influences the quality of interpolation results 
(Dorninger et al., 2008). Therefore the accuracy for the prediction of daily precipitation is lower compared to temperature, relative humidity and global radiation or to predictions based on monthly or yearly aggregated precipitation data (Diodato and Ceccarelli 2005; Hutchinson et al. 2009; Thornton et al., 1997; Vicente-Serrano et al., 2003).

Like precipitation wind speed measurements also exhibit a high spatio-temporal variability and the interpolation method consequently yielded lower estimates of quality. Nevertheless, the error was of the same magnitude compared to other studies (Luo et al., 2008).

Interpolation of global radiation generally achieved better results than precipitation and wind speed. The relatively high MAE in our work could be attributed to the lower set of source stations that could be used for interpolation compared to other variables. To solve the problem of a low station density other approaches use additional meteorological variables, e.g. sunshine duration, topographic information or combined methods for modelling solar radiation (Kang et al., 2002; Miller et al., 2008; Thornton et al., 1997). The accurate results which were obtained from the interpolation of air temperature and relative humidity indicate that the inclusion of both variables could support the modelling of solar radiation.

Interpolated and measured time series at the DWD stations correlated generally closer than interpolated and measured time series at the forest weather stations. These differences became crucial for wind speed and precipitation. For precipitation the higher prediction errors are more of random nature while for wind speed systematic deviation occurs. Obviously systematic differences occurred between both networks, which could partly be caused by wind protection climates due to the measurements on clear-cuttings. Furthermore, on seven sites the sensors were located above the canopy, where a systematic deviation due to a different surface roughness can be expected. For precipitation the homogenisation procedure could improve the correlation only a little. Therefore, especially the high prediction error for precipitation demonstrates the need for the on-site measurements within the ICP Forest Level II programme.

The impact of homogenisation was the highest for solar radiation and wind speed measurements. After visual inspection of the data and carefully studying the non-digital metadata, for solar radiation it became apparent that the reasons were mainly not measurement errors, but false data handling. Measurements of net radiation and measurements of a restricted spectral sensitivity (e.g. photosynthetic active radiation) were obviously stored as global radiation in the data base in some cases. These crucial mistakes could not be detected by simple range tests. A stricter handling of metadata could minimize such errors.

Precipitation and wind speed, both exhibit a high daily variability. The nature of inhomogenities in time series of both variables could be of long-term duration, e.g. due to instrument malfunction, or of short-term duration, e.g. due to obstacles in the vicinity of the instruments. The latter would cause fluctuations in the measurements, which depend on wind direction. In our work we could only detect long term inhomogeneities (>90 d) for both variables. We found the SNHT produced too unstable results when running to detect short-term inhomogeneities in time series of daily wind speed or precipitation data.

A general problem with the SNHT is to define a level which is assumed to represent the "true" level. In our work we found for minimum and maximum air temperatures a seasonal pattern where the differenced time series reached varying levels during winter and summer. It can not be precluded that this was caused by climate. Our method of adjusting the whole series to the same level did not account for that. This shows the need for developing an adequate objective method to select the reference level within the SNHT. Furthermore, a seasonal decomposition of the time series could be helpful.

We found significant deviations between measured and modelled climate data. We suppose that this was due to systematic differences in the environment of the two sets of weather stations: the stations of the DWD on the one hand which were used as source data for interpolation and the Level II weather stations on the other hand. Two main causes could be supposed: differences in the exposure of the weather stations due to obstacles and surface properties and differences in the energy/heat exchange between land and atmosphere due to landcover effects. Although both causes can not be clearly differentiated, to assess the impact of landcover on the systematic deviations, it is crucial to estimate the influence of obstacles on the measurements. Therefore the field situation around the sensors should be described carefully within the ICP Forest Level II database e.g. the distance of the sensors to the forest edge should be considered as a component of the metadata. The influence of the environment on weather station based measurements has been widely discussed (Gallo et al., 1996; Peterson, 2003) and especially forests have an impact on local climate (Bala et al., 2007; Klingaman et al., 2008; O'Neal et al., 2009; Strack et al., 2008). Moreover, weather station measurements in forested environments are underrepresented in national meteorological networks in industrialized countries. Therefore systematic deviations between the two sets of climate time series can be expected. Therefore the ICP Forests Level II climate data set can become a valuable source to study landcover impacts on climate, e.g. for validation of vegetation feedback models. Furthermore, the significant bias between both datasets demonstrates that the inclusion of land use categories or proxy measures in the interpolation method could significantly improve the results.

We concluded that the SNHT should be included within the QA/QC - programme of ICP Forests Level II, which makes it necessary to acquire homogenised climate date from national meteorological networks. We also concluded that the interpolation of climate in forested areas with daily resolution inhibits significant biases. We assume that the ICP Forests Level II climate data set could become a valuable resource to study landcover impacts on weather station based measurements. Furthermore, we expect that the homogenised climate data set will improve the on site modelling of water budgets within the ICP Forests Level II programm. 
Acknowledgements: This work was supported by the EU LIFE+ project "Further Development and Implementation of an EU-level Forest Monitoring System (FutMon)"'. The ICP Forests Level II runs under the UNECE convention of "Long Range Transboundary Air Pollution (CLRTAP)".The climate data were collected by the German federal states. We acknowledge DWD and PIK for providing the homogenised climate time series of the German weather stations.

\section{REFERENCES}

Alexandersson H., 1986. A homogeneity test applied to precipitation data. J. Climatol. 6: 661-675.

Bala G., Caldeira K., Wickett M., Phillips T.J., Lobell D.B., Delire C., and Mirin A., 2007. Combined climate and carbon-cycle effects of largescale deforestation. Proc. Natl. Acad. Sci. USA 104: 6550-6555.

Daly C., Halbleib M., Smith J.I., Gibson W.P., Doggett M.K., Taylor G.H., Curtis J., and Pasteris P.P., 2008. Physiographically sensitive mapping of climatological temperature and precipitation across the conterminous United States. Int. J. Climatol. 28: 2031-2064.

De Vries W., Vel E., Reinds G.J., Deelstra H., Klap J.M., Leeters E.E.J.M., Hendriks C.M.A., Kerkvoorden M., Landmann G., Herkendell J., Haussmann T., and Erisman J.W., 2003. Intensive monitoring of forest ecosystems in Europe - 1. Objectives, set-up and evaluation strategy. For. Ecol. Manage. 174: 77-95.

Diodato N. and Ceccarelli M., 2005. Interpolation processes using multivariate geostatistics for mapping of climatological precipitation mean in the Sannio Mountains (southern Italy). Earth. Surf. Proc. Land. 30: 259-268.

Dorninger M., Schneider S., and Steinacker R., 2008. On the interpolation of precipitation data over complex terrain. Meteorol. Atmos. Phys. 101: 175-189.

Ferretti M., Bussotti F., Cenni E., and Cozzi A., 1999. Implementation of quality assurance procedures in the Italian programs of forest condition monitoring. Water Air Soil Pollut. 116: 371-376.

Gallo K.P., Easterling D.R., and Peterson T.C., 1996. The influence of land use/land cover on climatological values of the diurnal temperature range. J. Climate 9: 2941-2944.

Houston T.D. and Hiederer R., 2009. Applying quality assurance procedures to environmental monitoring data: a case study. J. Environ. Monitor. 11: 774-781.

Hutchinson M.F., Mckenney D.W., Lawrence K., Pedlar J.H., Hopkinson R.F., Milewska E., and Papadopol P., 2009. Development and testing of Canada-wide interpolated spatial models of daily minimummaximum temperature and precipitation for 1961-2003. J. Appl. Meteorol. Clim. 48: 725-741.

Innes J.L., 1994. Climatic sensitivity of temperate forests. Environ. Pollut. 83: 237-243.

Kang S.Y., Kim S., and Lee D., 2002. Spatial and temporal patterns of solar radiation based on topography and air temperature. Can. J. For. Res. 32: 487-497.
Klingaman N.P., Butke J., Leathers D.J., Brinson K.R., and Nickl E., 2008. Mesoscale simulations of the land surface effects of historical logging in a moist continental climate regime. J. Appl. Meteorol. Clim. 47: 2166-2182.

Luo W., Taylor M.C., and Parker S.R., 2008. A comparison of spatial interpolation methods to estimate continuous wind speed surfaces using irregularly distributed data from England and Wales. Int. J. Climatol. 28: 947-959.

Miller D.G., Rivington M., Matthews K.B., Buchan K., and Bellocchi G., 2008. Testing the spatial applicability of the Johnson-Woodward method for estimating solar radiation from sunshine duration data. Agric. For. Meteorol. 148: 466-480.

O’Neal M.A., Hanson B., Leathers D.J., and Goldstein A., 2009. Estimating land cover - induced increases in daytime summer temperatures near Mt. Adans, Washington. Phys. Geogr. 30: 130-143.

Österle H., Werner P.C., and Gerstengarbe F.W., 2006. Qualitätsprüfung, Ergänzung und Homogenisierung der täglichen Datenreihen in Deutschland, 1951-2003: ein neuer Datensatz. 7. Deutsche Klimatagung. Klimatrends: Vergangenheit und Zukunft. http://www. meteo.physik.uni-muenchen.de/dkt/poster.html.

Peterson T.C., 2003. Assessment of urban versus rural in situ surface temperatures in the contiguous United States: No difference found. J. Climate 16: 2941-2959.

Peterson T.C., Easterling D.R., Karl T.R., Groisman P., Nicholls N., Plummer N., Torok S., Auer I., Boehm R., Gullett D., Vincent L., Heino R., Tuomenvirta H., Mestre O., Szentimrey T., Salinger J., Forland E.J., Hanssen-Bauer I., Alexandersson H., Jones P., and Parker D., 1998. Homogeneity adjustments of in situ atmospheric climate data: A review. Int. J. Climatol. 18: 1493-1517.

Solberg S., Dobbertin M., Reinds G. J., Lange H., Andreassen K., Garcia Fernandez P., Hildingsson A., and de Vries W., 2009. Analyses of the impact of changes in atmospheric deposition and climate on forest growth in European monitoring plots: A stand growth approach. For. Ecol. Manage. 258: 1735-1750.

Spadavecchia L. and Wiliams M., 2009. Can spatio-temporal geostatistical methods improve high resolution regionalisation of meteorological variables? Agric. For. Meteorol. 149: 1105-1117.

Stahl K., Moore R.D., Floyer J.A., Asplin M.G., and McKendry I.G., 2006. Comparison of approaches in a large region with complex topography and highly variable station density. Agric. For. Meteorol. 139: 224-236.

Strack J.E., Pielke R.A., Steyaert L.T., and Knox R.G., 2008. Sensitivity of June near-surface temperatures and precipitation in the eastern United States to historical land cover changes since European settlement. Water Resour. Res. 44: W11401.

Thornton F.C., Running S.W., and White M.A., 1997. Generating surfaces of daily meteorological variables over large regions of complex terrain. J. Hydrol. 190: 214-251.

Vicente-Serrano S.M., Saz-Sanchez M.A., and Cuadrat J.M., 2003. Comparative analysis of interpolation methods in the middle Ebro Valley (Spain): application to annual precipitation and temperature. Clim. Res. 24: 161-180. 